\title{
Patient Preference for Treatment Mode of Biologics in Rheumatoid Arthritis: A 2020 Web-based Survey in Japan
}

\author{
Mitsumasa Kishimoto (D) · Fumiko Yamairi (D) · Noriko Sato (D) • \\ Jun Kobayashi · Saori Yamauchi · Tomohisa Iwasaki
}

Received: April 12, 2021 / Accepted: May 20, 2021 / Published online: June 5, 2021

(C) The Author(s) 2021

\section{ABSTRACT}

Introduction: Although the proportion of patients with rheumatoid arthritis (RA) using biologic disease-modifying antirheumatic drugs (bDMARDs) has increased steadily, the relationship between patient background and

Supplementary Information The online version contains supplementary material available at https:// doi.org/10.1007/s40744-021-00325-9.

M. Kishimoto $(\bowtie)$

Department of Nephrology and Rheumatology,

Kyorin University School of Medicine, 6-20-2

Shinkawa Mitaka, Tokyo 181-8611, Japan

e-mail: kishimotomi@gmail.com

F. Yamairi · N. Sato

Medical Intelligence Department, Ikuyaku.

Integrated Value Development Division, Mitsubishi

Tanabe Pharma Corporation, Tokyo, Japan

J. Kobayashi

Medical Affairs Department, Ikuyaku. Integrated

Value Development Division, Mitsubishi Tanabe

Pharma Corporation, Tokyo, Japan

S. Yamauchi

Medical Affairs Department, Ikuyaku. Integrated Value Development Division, Mitsubishi Tanabe Pharma Corporation, Osaka, Japan

T. Iwasaki

Data Science Department, Ikuyaku. Integrated Value Development Division, Mitsubishi Tanabe Pharma Corporation, Tokyo, Japan preference for bDMARDs has not been fully investigated.

Methods: We conducted a web-based questionnaire survey among patients aged $\geq 20$ years with RA receiving bDMARDs. Participants were recruited through an internet research company in Japan. Study endpoints included factors affecting the preferred bDMARD treatment mode, namely, in-hospital intravenous infusion (infusion), in-hospital subcutaneous injection (in-hospital injection), or self-administered subcutaneous injection (self-injection), and discrepancies between the current and preferred treatment mode.

Results: Of the 400 patients surveyed for preferred treatment mode, $15.3 \%$ preferred infusion, $18.0 \%$ preferred in-hospital injection, and $66.8 \%$ preferred self-injection. A preference for infusion (odds ratio [OR] 2.218 and 6.165) and in-hospital injection (OR 4.735 and 6.026) versus self-injection was significantly associated with higher current frequency of hospital visits and anxiety or other hurdles related to self-injection. A flexible administration setting was significantly associated with a preference for self-injection versus infusion (OR 0.401) and versus in-hospital injection (OR 0.445). Further, age ( $<40$ vs. $\geq 60$ years) was significantly associated with a preference for self-injection versus in-hospital injection (OR 0.120). Many patients reported no discrepancy between their current and preferred treatment mode (patients receiving infusion, 68.0\%; in-hospital injection, 
71.2\%; and self-injection, 94.0\%). However, > $90 \%$ of patients responded that they would change their current mode in the future following a recommendation by a medical professional, aging, or a change in RA symptoms.

Conclusions: This web-based survey showed that patient preference for bDMARD treatment mode was significantly associated with age, frequency of hospital visits, flexible administration setting, and anxiety or other hurdles to self-injection. Changes in patient background which affect the preferred treatment mode should be considered in decision-making for RA therapy with bDMARDs.

Trial registration: R000048089 (UMIN-CTR)

Keywords: bDMARD; Biologics; COVID-19; Patient preferences; Rheumatoid arthritis; Selfadministered; Treatment mode; Web-based survey

\section{Key Summary Points}

\section{Why carry out this study?}

Increased use of biologic diseasemodifying antirheumatic drugs (bDMARDs) and wider bDMARD options for the treatment of rheumatoid arthritis (RA) may allow physicians to select or switch bDMARDs to better fit patient needs and preferences.

Patient preferences for treatment mode of bDMARDs in RA have not been fully investigated.

Identifying patient preferences regarding the treatment mode of bDMARDs and the triggers influencing patient preference to change between bDMARD options will help tailor selection of the optimal treatment for each patient.

\section{What was learned from the study?}

Age, frequency of hospital visits, flexible administration setting, and anxiety or other hurdles related to self-administered subcutaneous (SC) injection affected the treatment mode choice.
Although many patients did not report a discrepancy between their current and preferred treatment mode, approximately $30 \%$ of patients currently receiving inhospital intravenous infusion or inhospital SC injection and $6.0 \%$ currently receiving self-administered SC injection reported a discrepancy between their current and preferred treatment mode.

More than $90 \%$ of patients expressed a willingness to change treatment mode if recommended to do so by a medical professional, or if it became necessary due to aging or changes in their RA symptoms.

\section{DIGITAL FEATURES}

This article is published with digital features, including a summary slide, to facilitate understanding of the article. To view digital features for this article go to https://doi.org/10.6084/ m9.figshare.14618883.

\section{INTRODUCTION}

Rheumatoid arthritis (RA) is an inflammatory autoimmune disease characterized by chronic articular synovitis [1]. Disease-modifying antirheumatic drugs (DMARDs) are the mainstay of therapy, with the recommended treatment goal of sustained remission or low disease activity [2]. Several classes of DMARDs are available, including conventional synthetic DMARDs (e.g., methotrexate), biologic DMARDs (bDMARDs; i.e., tumor necrosis factor inhibitors [TNFis], interleukin-6 receptor inhibitors, and a T-cell costimulation modulator), and targeted synthetic DMARDs (e.g., Janus kinase inhibitors). An anti-RANKL antibody is also used to treat RA in Japan [3].

Treatment decisions should be taken in consideration of both patient- and therapy-related factors. These include disease activity, comorbidities, degree of joint structural damage, and safety issues [2]. Shared decision-making (SDM) should also include consideration of 
patient preferences and values regarding drug administration route, or in other words, the treatment mode [4].

The proportion of patients with RA using bDMARDs has increased steadily, even after the availability of Janus kinase inhibitors [5]. Several administration route options for bDMARDs are also now available [6]. However, although several studies have clearly shown a preference for oral administration (e.g., targeted synthetic DMARDs) among patients with RA [7-10], no comprehensive investigation of patient preferences for treatment mode with bDMARDs has yet appeared. A 2008 study of patient preferences for three TNFis among bDMARD-naïve patients reported a preference toward in-hospital bDMARD use among elderly patients and a preference for self-administration among nonelderly patients [11]. Nolla et al. reported a preference in patients for self-administration among nine bDMARDs, but did not report factors related to preference [12]. We speculated that a better understanding of patient preferences for the treatment mode of bDMARDs, including those at the start of administration and those triggering a subsequent change in preference, would facilitate treatment selection and likely lead to improvements in patient satisfaction.

Here, we report the results of a web-based questionnaire survey conducted in patients with RA to investigate the relationship between patient characteristics and preferences for bDMARD treatment mode, namely in-hospital intravenous (IV) infusion, in-hospital subcutaneous (SC) injection, and self-administered SC injection.

\section{METHODS}

\section{Study Design and Patients}

The study was conducted as a web-based questionnaire survey of patients with RA receiving bDMARDs in Japan. Participants were recruited from among registrants of an internet research company (Rakuten Research Inc., Tokyo, Japan) who consented to participate in the survey. Enrolled patients were aged $\geq 20$ years, had a diagnosis of RA under either inpatient or outpatient management, attended regular hospital visits for RA management (at least once every 3 months), and were using bDMARDs for the treatment of RA. Patients were excluded if consent was withdrawn after agreeing to participate or if they were considered to be inappropriate as survey participants by the investigator.

The study was conducted in compliance with the Declaration of Helsinki of the World Medical Association (revised October 2013) and the Ethical Guidelines for Medical and Health Research Involving Human Subjects (partially revised 28 February 2017). Approval for the study was obtained from the Clinical Research Review Board of Takahashi Clinic on 20 October 2020. This study was registered in the UMIN clinical trial registry (registration number: R000048089).

\section{Survey Administration}

Following email notification and confirmation of consent, a questionnaire survey was administered via the survey website from 23 October to 2 November 2020. Responses were scrutinized for data entry discrepancies, including the exclusion of multiple survey responses by the same person.

\section{Survey Items}

Survey items included basic personal and demographic information, including sex, age, family composition, and employment status; disease characteristics, including disease duration; functional disability, as assessed by the Japanese version of the Stanford Health Assessment Questionnaire (J-HAQ); impact on work productivity, as assessed using a modified version of question 5 of the Work Productivity and Activity Impairment Questionnaire: General Health version 2.0 (WPAI-GH) [13, 14]; and the presence or absence of comorbidities. In particular, the presence of physical dysfunction was determined by a J-HAQ score of $\geq 0.5$ and functional remission was determined by a score of $<0.5$ [15]. To measure impact on work 
Table 1 Patient characteristics

\begin{tabular}{|c|c|}
\hline Characteristic & $\begin{array}{l}\text { Values }(N=400 \\
\text { patients) }\end{array}$ \\
\hline \multicolumn{2}{|l|}{ Sex, $n(\%)$} \\
\hline Male & $122(30.5)$ \\
\hline Female & $278(69.5)$ \\
\hline Age, years, mean \pm SD & $55.7 \pm 12.7$ \\
\hline \multicolumn{2}{|l|}{ Age group, years, $n(\%)$} \\
\hline $20-29$ & $9(2.3)$ \\
\hline $30-39$ & $38(9.5)$ \\
\hline $40-49$ & $81(20.3)$ \\
\hline $50-59$ & $96(24.0)$ \\
\hline $60-69$ & $120(30.0)$ \\
\hline$\geq 70$ & $56(14.0)$ \\
\hline $\begin{array}{l}\text { Duration of } \mathrm{RA}^{\mathrm{a}} \text {, years, } \\
\text { mean } \pm \mathrm{SD}\end{array}$ & $14.1 \pm 9.8$ \\
\hline $\mathrm{J}$-HAQ score, mean $\pm \mathrm{SD}$ & $0.7 \pm 0.8$ \\
\hline \multicolumn{2}{|l|}{ J-HAQ score, $n(\%)$} \\
\hline$<0.5$ & $201(50.3)$ \\
\hline 0.5 to $<1.0$ & $79(19.8)$ \\
\hline 1.0 to $<1.5$ & $45(11.3)$ \\
\hline 1.5 to $<2.0$ & $37(9.3)$ \\
\hline 2.0 to $<2.5$ & $24(6.0)$ \\
\hline $2.5-3.0$ & $14(3.5)$ \\
\hline \multicolumn{2}{|c|}{ Current bDMARD mode, $n(\%)$} \\
\hline Infusion & $75(18.8)$ \\
\hline Subcutaneous (in-hospital) & $59(14.8)$ \\
\hline Subcutaneous (autologous) & $258(64.5)$ \\
\hline Subcutaneous (caregiver) & $8(2.0)$ \\
\hline \multicolumn{2}{|c|}{ Duration of current bDMARD, $n(\%)$} \\
\hline$<1$ year & $37(9.3)$ \\
\hline 1 to $<2$ years & $51(12.8)$ \\
\hline 2 to $<3$ years & $45(11.3)$ \\
\hline 3 to $<5$ years & $66(16.5)$ \\
\hline$\geq 5$ years & $201(50.3)$ \\
\hline
\end{tabular}

Table 1 continued

\begin{tabular}{ll}
\hline Characteristic & $\begin{array}{l}\text { Values }(\boldsymbol{N} \\
\text { patients })\end{array}$ \\
\hline Current bDMARD ${ }^{\mathrm{b}}, n(\%)$ & \\
Adalimumab & $46(11.5)$ \\
Certolizumab pegol & $26(6.5)$ \\
Etanercept & $62(15.5)$ \\
Golimumab & $29(7.3)$ \\
Infliximab & $22(5.5)$ \\
Etanercept BS & $27(6.8)$ \\
Infliximab BS & $5(1.3)$ \\
Sarilumab & $13(3.3)$ \\
Tocilizumab & $106(26.5)$ \\
Abatacept & $59(14.8)$ \\
Denosumab & $5(1.3)$ \\
Concomitant medication, $n(\%)$ & \\
Yes & $353(88.3)$ \\
No & $47(11.8)$
\end{tabular}

Patient preference was shared with the physician in decision-making process for the current treatment drug No $242(60.5)$

Yes $152(38.0)$

Other $6(1.5)$

bDMARD Biologic disease-modifying antirheumatic drugs, $J$-HAQ Japanese version of the Stanford Health Assessment Questionnaire, $R A$ rheumatoid arthritis, $S D$ standard deviation

${ }^{a}$ Duration of RA was calculated as the current age minus the age at diagnosis

b Denosumab, an antiresorptive drug, is approved in Japan for the treatment of RA, and was therefore included in the study. Rituximab was not included as a bDMARD in the study because it is not indicated for the treatment of RA in Japan

productivity, the term "work" was expanded to "work and household chores"; in this context, we used question 5 (impact on productivity during work or performing household chores) 
(a)

\section{Current treatment mode of bDMARD}

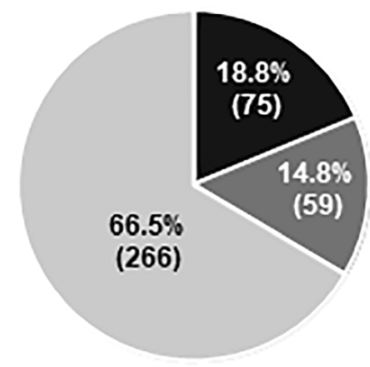

In-hospital IV infusion (b)

\section{Preferred treatment mode of bDMARD}

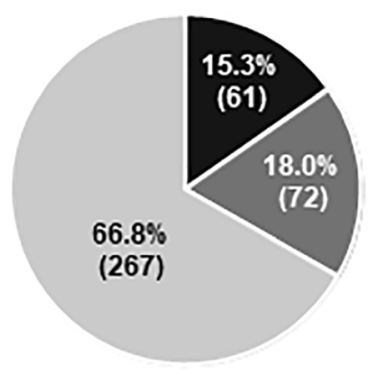

Self-administered SC injection

Fig. 1 Current (a) and preferred (b) treatment mode of bDMARDs presented as the percentage and number of patients (parentheses). $b D M A R D$ Biologic disease-modifying antirheumatic drug, $I V$ intravenous, $S C$ subcutaneous

of the WPAI-GH and graded the answer using a Likert scale of $0-10$ points, in which 0 indicated the lowest degree.

Additional survey items included information on the type of institution providing the patient's outpatient care (hospital or clinic), time required for outpatient visits, current frequency of outpatient visits, and means of transportation to the institution; currently used bDMARD, duration of its use, and use of other non-biologic drugs for RA (with/without); decision-making for the currently used drug (whether decision-making took into account the patient's preference); monthly cost of RA treatment; current treatment mode for bDMARD and preferred mode; and the patient's thoughts on their RA treatment (using a 5-point scale) (see Electronic Supplementary Material [ESM] Table S1). For patients whose current bDMARD treatment mode was also their preferred mode, the reason they did not wish to change was also recorded. Patients whose current mode differed from their preferred modes were asked why they were unable to receive their preferred mode. All patients were asked whether they foresaw an opportunity for their treatment mode to be changed in the future. Additionally, we evaluated the effect of the 2019 novel coronavirus disease (COVID-19) on the frequency of hospital visits and changes in treatment mode.
The primary endpoint was factors affecting selection of the patient's preferred bDMARD treatment mode. Secondary endpoints were the presence/absence of a difference between the patient's current and preferred bDMARD treatment mode (and reasons for this), and the patient's willingness to change the treatment mode in the future.

\section{Statistical Analysis}

The target sample size was calculated to allow interval estimation with constant accuracy (assuming a population size of approximately 130,000 bDMARD-treated RA patients and an expected response rate of 50\%). A sample size of 384 was calculated to achieve an interval estimate width of $\pm 5 \%$, and the target study sample size was set at 400 to ensure 384 cases.

Analyses included simple tabulation/crosstabulation, comparison of patient background by preferred treatment mode, and multinomial logistic regression analysis to explore factors relevant to preferred treatment mode. Statistical tests were two-sided with a significance level of $5 \%$. Two-sided confidence intervals (CIs) were determined with a confidence level of $95 \%$.

For all questions, categorical variables were calculated as frequencies, and continuous variables as descriptive (mean, standard deviation [SD]) and/or converted to categorical variables and presented as a frequency where appropriate. 
Table 2 Factors influencing preferred treatment mode (univariate analysis)

\begin{tabular}{|c|c|c|c|c|c|c|}
\hline \multirow[t]{2}{*}{ Survey item } & \multirow[t]{2}{*}{ Category } & \multirow{2}{*}{$\begin{array}{l}\text { Overall patient } \\
\text { population } \\
(N=400)\end{array}$} & \multicolumn{4}{|c|}{ Preferred treatment mode } \\
\hline & & & $\begin{array}{l}\text { In-hospital IV } \\
\text { infusion } \\
(n=61)\end{array}$ & $\begin{array}{l}\text { In-hospital SC } \\
\text { injection } \\
(n=72)\end{array}$ & $\begin{array}{l}\text { Self- } \\
\text { administered } \\
\text { SC injection } \\
(n=267)\end{array}$ & $p$ value \\
\hline \multirow[t]{2}{*}{ Sex } & Male & $122(30.5)$ & $22(36.1)$ & $27(37.5)$ & $73(27.3)$ & 0.149 \\
\hline & Female & $278(69.5)$ & $39(63.9)$ & $45(62.5)$ & $194(72.7)$ & \\
\hline \multirow[t]{3}{*}{ Age (years) } & $<40$ & $47(11.8)$ & $5(8.2)$ & $2(2.8)$ & $40(15.0)$ & 0.061 \\
\hline & $40-59$ & $177(44.3)$ & $28(45.9)$ & $35(48.6)$ & $114(42.7)$ & \\
\hline & $\geq 60$ & $176(44.0)$ & $28(45.9)$ & $35(48.6)$ & $113(42.3)$ & \\
\hline $\begin{array}{l}\text { Duration of RA } \\
\text { (years), mean } \pm \\
\text { SD }\end{array}$ & & $14.1 \pm 9.8$ & $14.6 \pm 9.1$ & $14.2 \pm 11.3$ & $14.0 \pm 9.6$ & 0.904 \\
\hline \multirow[t]{2}{*}{ J-HAQ score } & $<0.5$ & $201(50.3)$ & $35(57.4)$ & $33(45.8)$ & $133(49.8)$ & 0.402 \\
\hline & $0.5-3$ & $199(49.8)$ & $26(42.6)$ & $39(54.2)$ & $134(50.2)$ & \\
\hline \multirow{3}{*}{$\begin{array}{l}\text { Duration of current } \\
\text { bDMARD use } \\
\text { (years) }\end{array}$} & $<2$ & $88(22.0)$ & $8(13.1)$ & $13(18.1)$ & $67(25.1)$ & 0.153 \\
\hline & $2-5$ & $111(27.8)$ & $15(24.6)$ & $23(31.9)$ & $73(27.3)$ & \\
\hline & $>5$ & $201(50.3)$ & $38(62.3)$ & $36(50.0)$ & $127(47.6)$ & \\
\hline \multirow{2}{*}{$\begin{array}{l}\text { Concomitant } \\
\text { medication }\end{array}$} & Yes & $353(88.3)$ & $52(85.2)$ & $65(90.3)$ & $236(88.4)$ & 0.663 \\
\hline & No & $47(11.8)$ & $9(14.8)$ & $7(9.7)$ & $31(11.6)$ & \\
\hline \multirow[t]{3}{*}{ RA therapy cost } & $<10,000$ yen & $120(30.0)$ & $20(32.8)$ & $27(37.5)$ & $73(27.3)$ & 0.480 \\
\hline & $\begin{array}{l}10,000 \\
\text { to }<30,000 \\
\text { yen }\end{array}$ & $149(37.3)$ & $21(34.4)$ & $26(36.1)$ & $102(38.2)$ & \\
\hline & $\geq 30,000$ yen & $131(32.8)$ & $20(32.8)$ & $19(26.4)$ & $92(34.5)$ & \\
\hline \multirow[t]{2}{*}{ Comorbidities } & Yes & $227(56.8)$ & $32(52.5)$ & $43(59.7)$ & $152(56.9)$ & 0.698 \\
\hline & No & $173(43.3)$ & $29(47.5)$ & $29(40.3)$ & $115(43.1)$ & \\
\hline \multirow[t]{2}{*}{ Type of institution } & Hospital & $286(71.5)$ & $45(73.8)$ & $50(69.4)$ & $191(71.5)$ & 0.859 \\
\hline & Clinic & $114(28.5)$ & $16(26.2)$ & $22(30.6)$ & $76(28.5)$ & \\
\hline \multirow[t]{2}{*}{ Frequency of visits } & $\begin{array}{l}\text { Once every } \\
1-4 \text { weeks }\end{array}$ & $175(43.8)$ & $35(57.4)$ & $53(73.6)$ & $87(32.6)$ & $<0.001$ \\
\hline & $\begin{array}{l}\text { Once every } \\
2-3 \text { months }\end{array}$ & $225(56.3)$ & $26(42.6)$ & $19(26.4)$ & $180(67.4)$ & \\
\hline
\end{tabular}


Table 2 continued

\begin{tabular}{|c|c|c|c|c|c|c|}
\hline \multirow[t]{2}{*}{ Survey item } & \multirow[t]{2}{*}{ Category } & \multirow{2}{*}{$\begin{array}{l}\text { Overall } \\
\text { patient } \\
\text { population } \\
(N=400)\end{array}$} & \multicolumn{4}{|c|}{ Preferred treatment mode } \\
\hline & & & $\begin{array}{l}\text { In-hospital } \\
\text { IV infusion } \\
(n=61)\end{array}$ & $\begin{array}{l}\text { In-hospital } \\
\text { SC } \\
\text { injection } \\
(n=72)\end{array}$ & $\begin{array}{l}\text { Self- } \\
\text { administered } \\
\text { SC injection } \\
(n=267)\end{array}$ & $p$ value \\
\hline \multirow{4}{*}{$\begin{array}{l}\text { Time required to visit the } \\
\text { institution }\end{array}$} & $<30 \mathrm{~min}$ & $232(58.0)$ & $34(55.7)$ & $46(63.9)$ & $152(56.9)$ & 0.391 \\
\hline & 30 & $126(31.5)$ & $23(37.7)$ & $21(29.2)$ & $82(30.7)$ & \\
\hline & to $<60 \mathrm{~min}$ & & & & & \\
\hline & $\geq 60 \mathrm{~min}$ & $42(10.5)$ & $4(6.6)$ & $5(6.9)$ & $33(12.4)$ & \\
\hline \multirow[t]{2}{*}{$\begin{array}{l}\text { Method of transportation to } \\
\text { the institution }\end{array}$} & $\begin{array}{l}\text { Voluntary } \\
\text { outpatient } \\
\text { visit }\end{array}$ & $316(79.0)$ & $50(82.0)$ & $56(77.8)$ & $210(78.7)$ & 0.815 \\
\hline & $\begin{array}{l}\text { Driving by } \\
\text { another } \\
\text { person }\end{array}$ & $84(21.0)$ & $11(18.0)$ & $16(22.2)$ & $57(21.3)$ & \\
\hline \multirow[t]{4}{*}{ Occupation } & $\begin{array}{l}\text { Non-regular } \\
\text { and self- } \\
\text { employed }\end{array}$ & $122(30.5)$ & $22(36.1)$ & $24(33.3)$ & $76(28.5)$ & 0.679 \\
\hline & $\begin{array}{l}\text { Full-time } \\
\text { employees }\end{array}$ & $95(23.8)$ & $16(26.2)$ & $16(22.2)$ & $63(23.6)$ & \\
\hline & $\begin{array}{l}\text { Students and } \\
\text { homemakers }\end{array}$ & $103(25.8)$ & $14(23.0)$ & $15(20.8)$ & $74(27.7)$ & \\
\hline & $\begin{array}{l}\text { Unemployed } \\
\text { and other }\end{array}$ & $80(20.0)$ & $9(14.8)$ & $17(23.6)$ & $54(20.2)$ & \\
\hline $\begin{array}{l}\text { Work productivity, mean } \pm \\
\text { SD }\end{array}$ & - & $2.6 \pm 2.9$ & $1.9 \pm 2.5$ & $2.8 \pm 3.0$ & $2.7 \pm 2.9$ & 0.063 \\
\hline \multirow[t]{2}{*}{ Cohabiting family } & Yes & $75(18.8)$ & $10(16.4)$ & $13(18.1)$ & $52(19.5)$ & 0.845 \\
\hline & No & $325(81.3)$ & $51(83.6)$ & $59(81.9)$ & $215(80.5)$ & \\
\hline \multirow{2}{*}{$\begin{array}{l}\text { Involvement in parenting, } \\
\text { caregiving, or assistance }\end{array}$} & Yes & $75(18.8)$ & $5(8.2)$ & $15(20.8)$ & $55(20.6)$ & 0.072 \\
\hline & No & $325(81.3)$ & $56(91.8)$ & $57(79.2)$ & $212(79.4)$ & \\
\hline \multirow{2}{*}{$\begin{array}{l}\text { Family members assist with } \\
\text { hospital visits and } \\
\text { injections }\end{array}$} & Yes & $68(17.0)$ & $18(29.5)$ & $14(19.4)$ & $36(13.5)$ & 0.009 \\
\hline & No & $332(83.0)$ & $43(70.5)$ & $58(80.6)$ & $231(86.5)$ & \\
\hline $\begin{array}{l}\text { Anxiety or other hurdles } \\
\text { related to self- } \\
\text { administering } S C \text { injection, } \\
\text { mean } \pm S^{a}\end{array}$ & - & $0.00 \pm 0.96$ & $0.85 \pm 0.76$ & $0.84 \pm 0.85$ & $-0.42 \pm 0.72$ & $<0.001$ \\
\hline
\end{tabular}


Table 2 continued

\begin{tabular}{|c|c|c|c|c|c|c|}
\hline \multirow[t]{2}{*}{ Survey item } & \multirow[t]{2}{*}{ Category } & \multirow{2}{*}{$\begin{array}{l}\text { Overall patient } \\
\text { population } \\
(N=400)\end{array}$} & \multicolumn{4}{|c|}{ Preferred treatment mode } \\
\hline & & & $\begin{array}{l}\text { In-hospital IV } \\
\text { infusion } \\
(n=61)\end{array}$ & $\begin{array}{l}\text { In-hospital SC } \\
\text { injection } \\
(n=72)\end{array}$ & $\begin{array}{l}\text { Self- } \\
\text { administered } \\
\text { SC injection } \\
(n=267)\end{array}$ & $p$ value \\
\hline $\begin{array}{l}\text { Burden of hospital } \\
\text { visits, mean } \pm \mathrm{SD}^{\mathrm{a}}\end{array}$ & - & $0.00 \pm 0.95$ & $-0.10 \pm 0.87$ & $-0.20 \pm 0.87$ & $0.07 \pm 0.98$ & 0.057 \\
\hline $\begin{array}{l}\text { Reliable or convenient } \\
\text { administration, } \\
\text { mean } \pm \mathrm{SD}^{\mathrm{a}}\end{array}$ & - & $0.00 \pm 0.87$ & $0.08 \pm 0.61$ & $0.05 \pm 0.78$ & $-0.03 \pm 0.95$ & 0.501 \\
\hline $\begin{array}{l}\text { Flexible administration } \\
\text { setting, mean } \pm \mathrm{SD}^{\mathrm{a}}\end{array}$ & - & $0.00 \pm 0.85$ & $-0.59 \pm 0.84$ & $-0.55 \pm 0.88$ & $0.28 \pm 0.68$ & $<0.001$ \\
\hline
\end{tabular}

Patients' thoughts on their treatment were summarized using factor analysis and collected as latent variables (factors). Exploratory factor analysis was performed using maximum likelihood estimation with promax rotation, and the factor scores of each respondent were calculated for each factor. To explore questionnaire items and factors affecting the preferred treatment mode (stratified by preferred treatment mode), $p$ values were calculated using the chi-square $\left(\chi^{2}\right)$ test for categorical variables and analysis of variance in treatment mode for continuous variables. Multinomial logistic regression analysis was performed using age, sex, and J-HAQ scores, as well as questionnaire items and factor scores with $p<0.20$ in the tests above as independent variables. Variables were selected by backward stepwise selection, with the significance level for input and elimination from the model set at 5\%. Age, sex, and J-HAQ scores were excluded from variable selection and were included in the final model. Data were analyzed with IBM SPSS Statistics version 26 (IBM Corp., Armonk, NY, USA).

\section{RESULTS}

\section{Patient Characteristics}

In total, 400 RA patients who met the inclusion criteria were included in the analysis. Of these 400 patients overall, $69.5 \%$ were female, the mean age was 55.7 years, and mean disease duration was 14.1 years (Table 1 ). The mean J-HAQ score was 0.7 , and approximately $50 \%$ of patients had reached functional remission.

\section{Treatment Mode of bDMARDs}

The proportions of patients currently receiving bDMARDs by treatment mode were $18.8 \%$ (75/ 400) for in-hospital IV infusion; 14.8\% (59/400) for in-hospital SC injection; and 66.5\% (266/ 400) for self-administered SC injection, including $2 \%(8 / 400)$ receiving caregiver-administered SC injection (Fig. 1a). The proportions of patients according to preferred treatment mode of bDMARD were $15.3 \%(61 / 400)$ for in-hospital IV infusion, $18.0 \%(72 / 400)$ for in-hospital SC injection, and $66.8 \%(267 / 400)$ for self-administered SC injection (Fig. 1b). 


\section{Factors Affecting Preference for bDMARD Treatment Mode}

Factor analysis of patient thoughts on treatment mode yielded the following factors: factor 1 , anxiety or other hurdles related to self-administered SC injection; factor 2, burden of hospital visits; factor 3 , reliable or convenient administration; and factor 4, a flexible administration setting (see ESM Table S1).

Univariate analysis to select candidate factors for multinomial logistic regression analysis identified the following factors with a $p<0.20$ : sex $(p=0.149)$; age $(p=0.061)$; duration of current bDMARD use $(p=0.153)$; current frequency of hospital visits $(p<0.001)$; work productivity $(p=0.063)$; involvement in parenting, caregiving, or assistance $(p=0.072)$; presence of family members who assist in hospital visits and injections $(p=0.009)$; anxiety or other hurdles related to self-administering the SC injection $(p<0.001) ; \quad$ burden of hospital visits $(p=0.057) ;$ and flexible administration setting $(p<0.001)$ (Table 2).

In the multinomial logistic regression analysis for in-hospital IV infusion versus self-administered SC injection, current frequency of hospital visits (once every 1-4 weeks vs. once every 2 or 3 months; odds ratio [OR] 2.218, 95\% CI 1.067-4.610), anxiety or other hurdles related to self-administered SC injection (OR 6.165, 95\% CI 3.766-10.093), and flexible administration setting (OR 0.401, 95\% CI 0.253-0.636) were significantly associated with a preference for treatment mode (Fig. 2).

In the multinomial logistic regression analysis for in-hospital SC injection versus self-administered SC injection, current frequency of hospital visits (once every 1-4 weeks vs. once every 2-3 months, OR 4.735, 95\% CI $2.271-9.872$ ), age (for $<40$ years vs. $\geq 60$ years; OR $0.120,95 \%$ CI $0.023-0.640$ ), anxiety or other hurdles related to self-administered SC injection (OR 6.026, 95\% CI 3.763-9.648), and flexible administration setting (OR 0.445, 95\% CI 0.283-0.699) were significantly associated with a preference for treatment mode (Fig. 2).

\section{Difference Between bDMARD Current and Preferred Treatment Mode}

Among patients currently receiving bDMARDs by in-hospital IV infusion, in-hospital SC injection, and self-administered SC injection, 68.0, 71.2, and 94.0\%, respectively, did not report a discrepancy between their current and preferred treatment mode of bDMARD (Fig. 3). The most common reason for not changing the current treatment mode (across all current bDMARD treatment modes) was lack of dissatisfaction with the current treatment mode (Fig. 4). The proportion of patients feeling anxious that the drug's effect was likely to be lost if the treatment mode was changed was greater among those currently receiving in-hospital IV infusion. The proportion who responded that the current treatment mode fit their current lifestyle was greater among those currently receiving self-administered SC injection.

The proportions of patients with a gap between their current and preferred treatment mode were $32.0 \%$ for in-hospital IV infusion, $28.8 \%$ for in-hospital SC injection, and $6.0 \%$ for self-administered SC injection (Fig. 3). The most common reasons for preferring but not receiving in-hospital IV infusion were "healthcare cost may increase upon switching" (4/10) and "RA status is good" (3/10) (Fig. 5). The major reasons for desiring but not receiving in-hospital SC injection were "physician does not recommend a treatment mode change" (14/30) and "RA status is good" (11/30) (Fig. 5). The major reasons given for desiring but not receiving self-administered SC injection were "patient is unsure of ability to self-administer the drug appropriately" (8/17) and "physician does not recommend a treatment mode change" (5/17) (Fig. 5).

\section{Willingness to Change bDMARD Treatment Mode in the Future}

A total of $7.0 \%(28 / 400)$ responded that they did not wish to change treatment mode; that is, 93.0\% (372/400) responded that they would change their treatment mode in the future for various reasons (Fig. 6). The most frequent 
In-hospital IV infusion versus self-administered SC injection

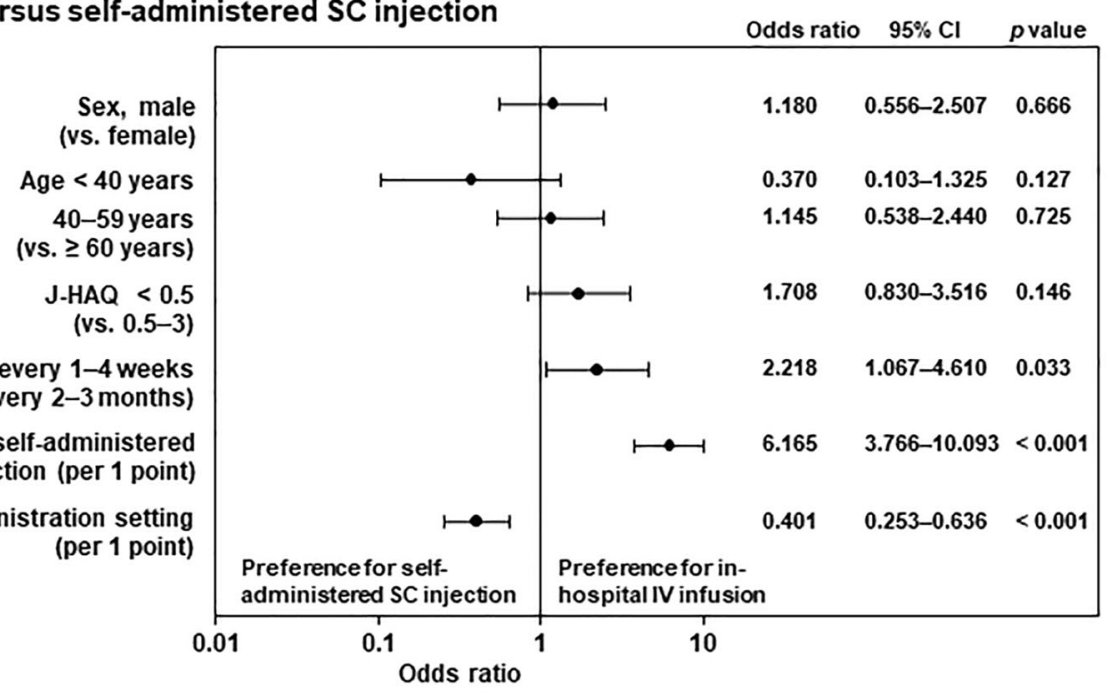

In-hospital SC injection versus self-administered SC injection

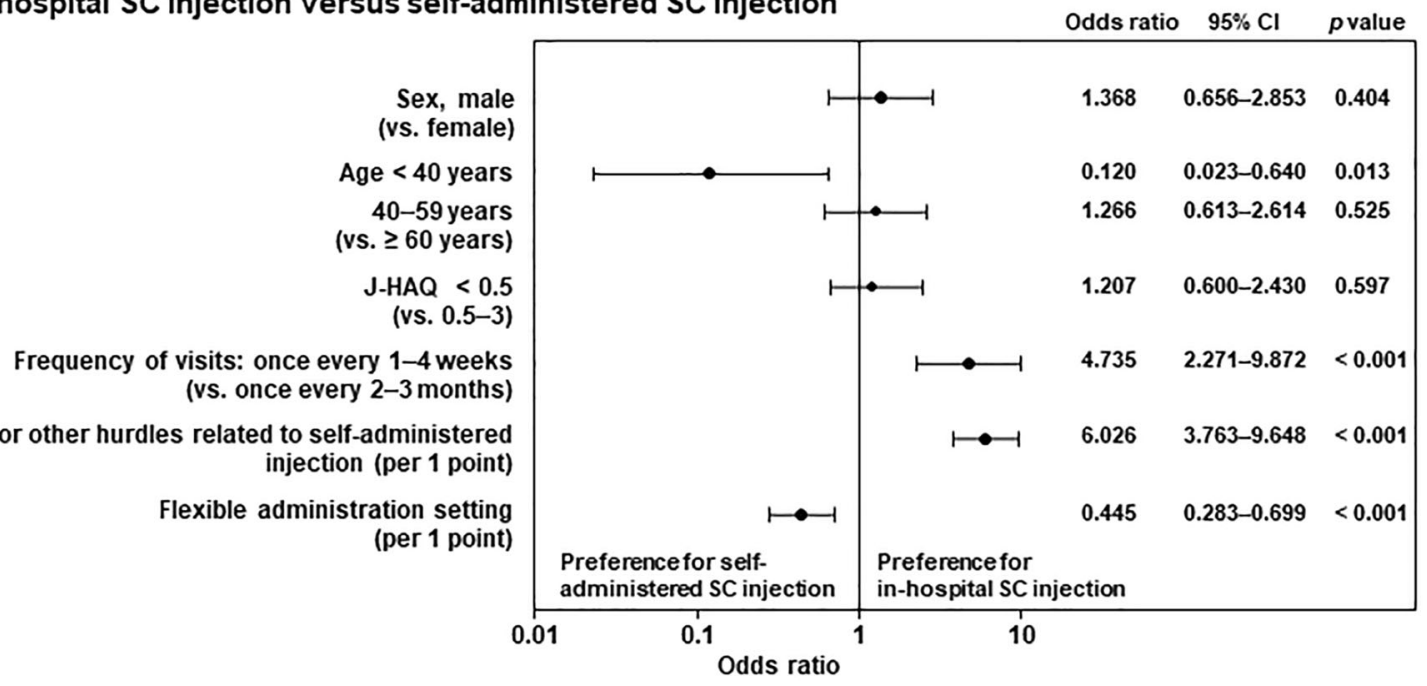

Fig. 2 Factors affecting selection of preferred bDMARD treatment mode. CI Confidence interval, J-HAQ Japanese version of the Stanford Health Assessment Questionnaire

reasons given for a change in current treatment mode were "switching recommended by a medical professional (e.g., physician or nurse)" and "change of RA symptoms (improved or worsened)." Patients whose current treatment mode was self-administered SC injection were more willing to change their treatment mode for the following reasons: "patient age increased," "change of RA symptoms (improved or worsened)," and "new drug released".

\section{Effect of COVID-19 on the Frequency of Hospital Visits and Changes in Treatment Mode}

Among all patients, $18.8 \%$ (75/400) reduced their frequency of patient visits to the hospital for RA management because of the spread of COVID-19 (see ESM Fig. S1a). Further, 2.0\% (8/ 400) of patients indicated that they wished to change their treatment mode immediately, $12.3 \%(49 / 400)$ wanted to change it in the future, and $3.0 \%(12 / 400)$ had already changed their treatment mode for this reason (see ESM 


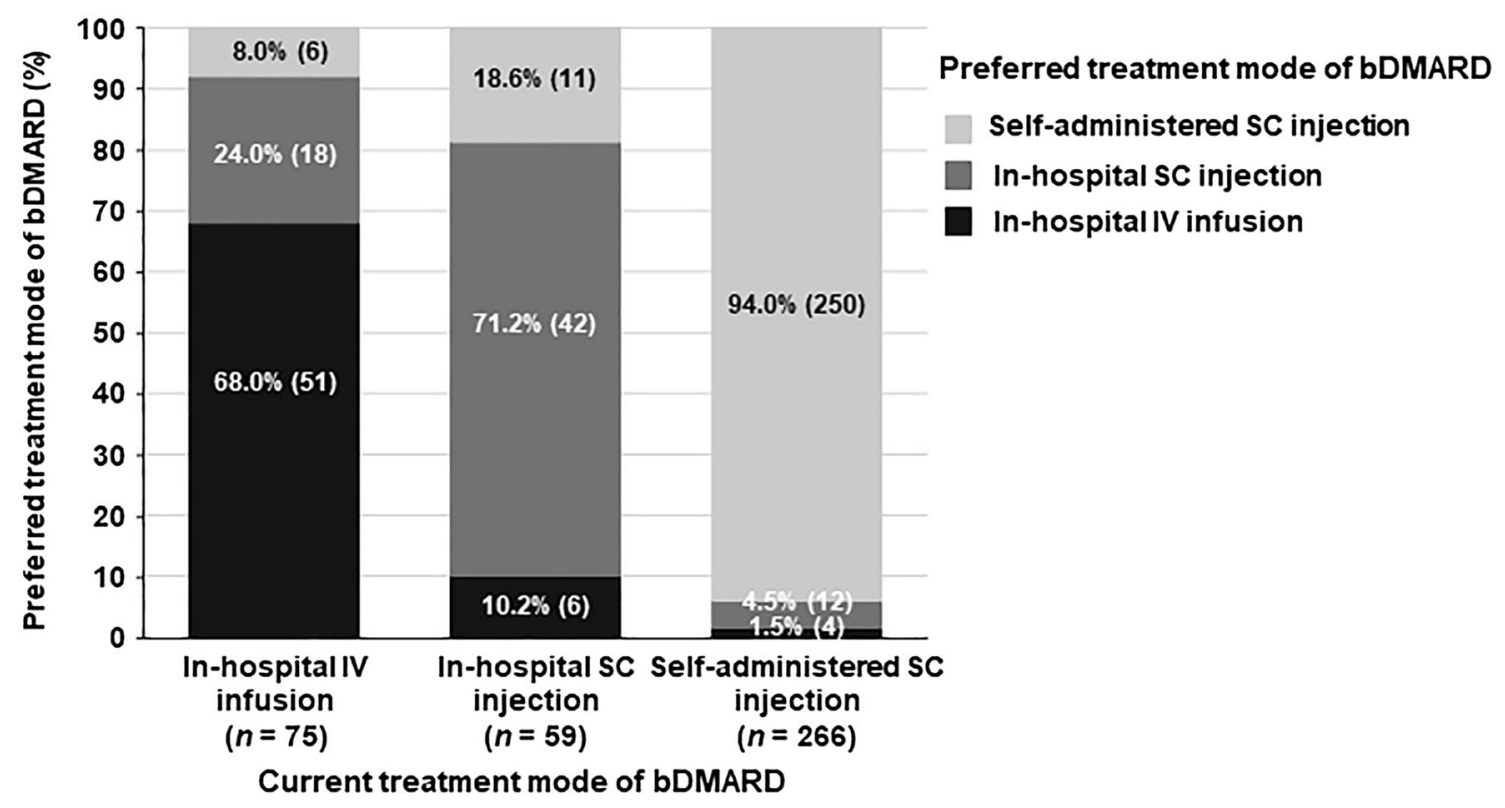

Fig. 3 Percentages of preferred bDMARD treatment mode by current treatment mode. Number of patients is indicated in parentheses

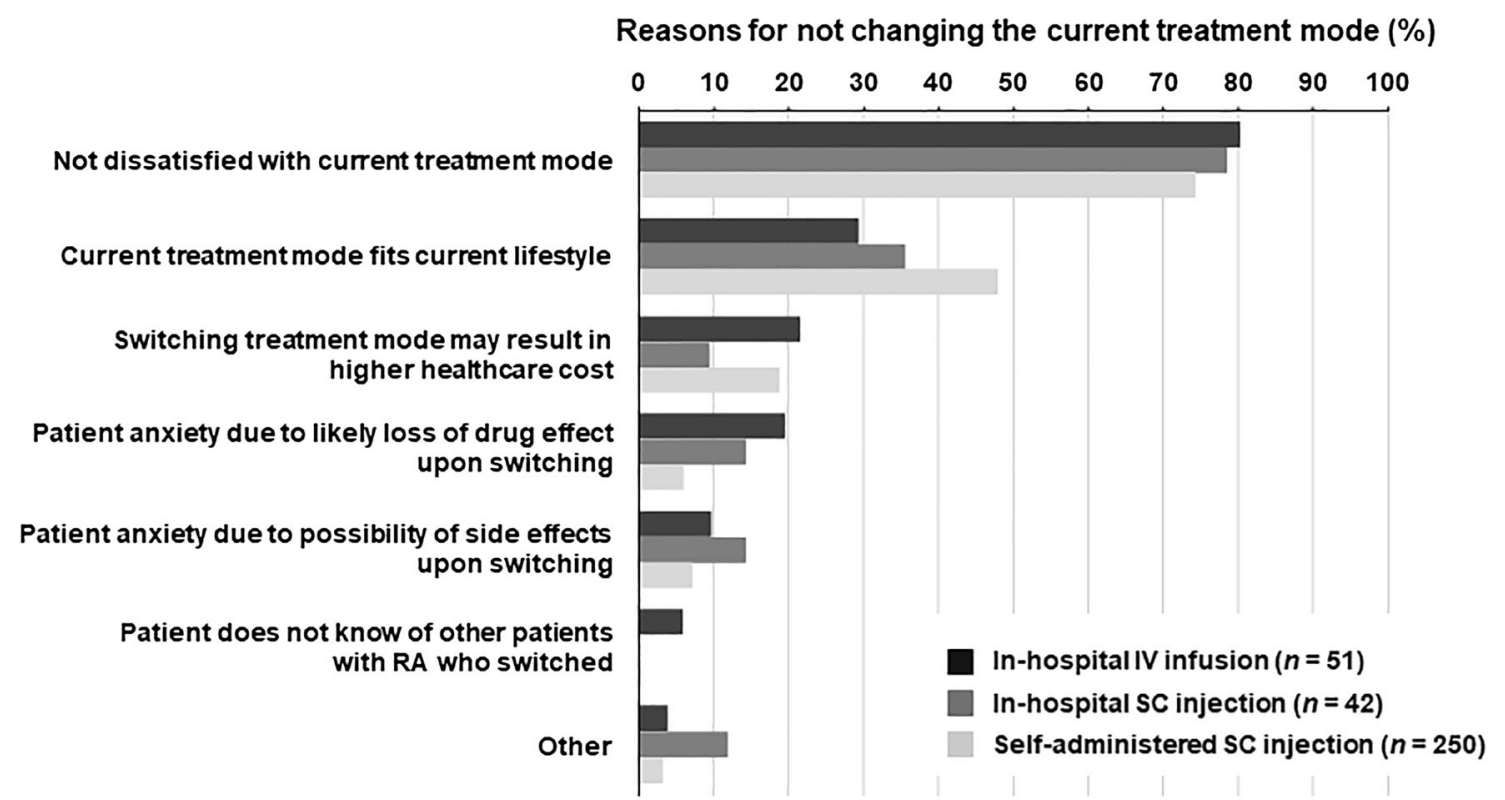

Fig. 4 Reasons for not changing the current treatment mode of bDMARD. Patients could select multiple answers. $R A$ Rheumatoid arthritis

Fig. S1b). Further, 97.0\% (388/400) of these patients with reduced frequency of visits indicated that they had not changed treatment mode because of COVID-19 (see ESM Fig. S1b).
The proportion by treatment mode was $97.3 \%$ (73/75) for those with in-hospital IV infusion, 91.5\% (54/59) for in-hospital SC injection, and 


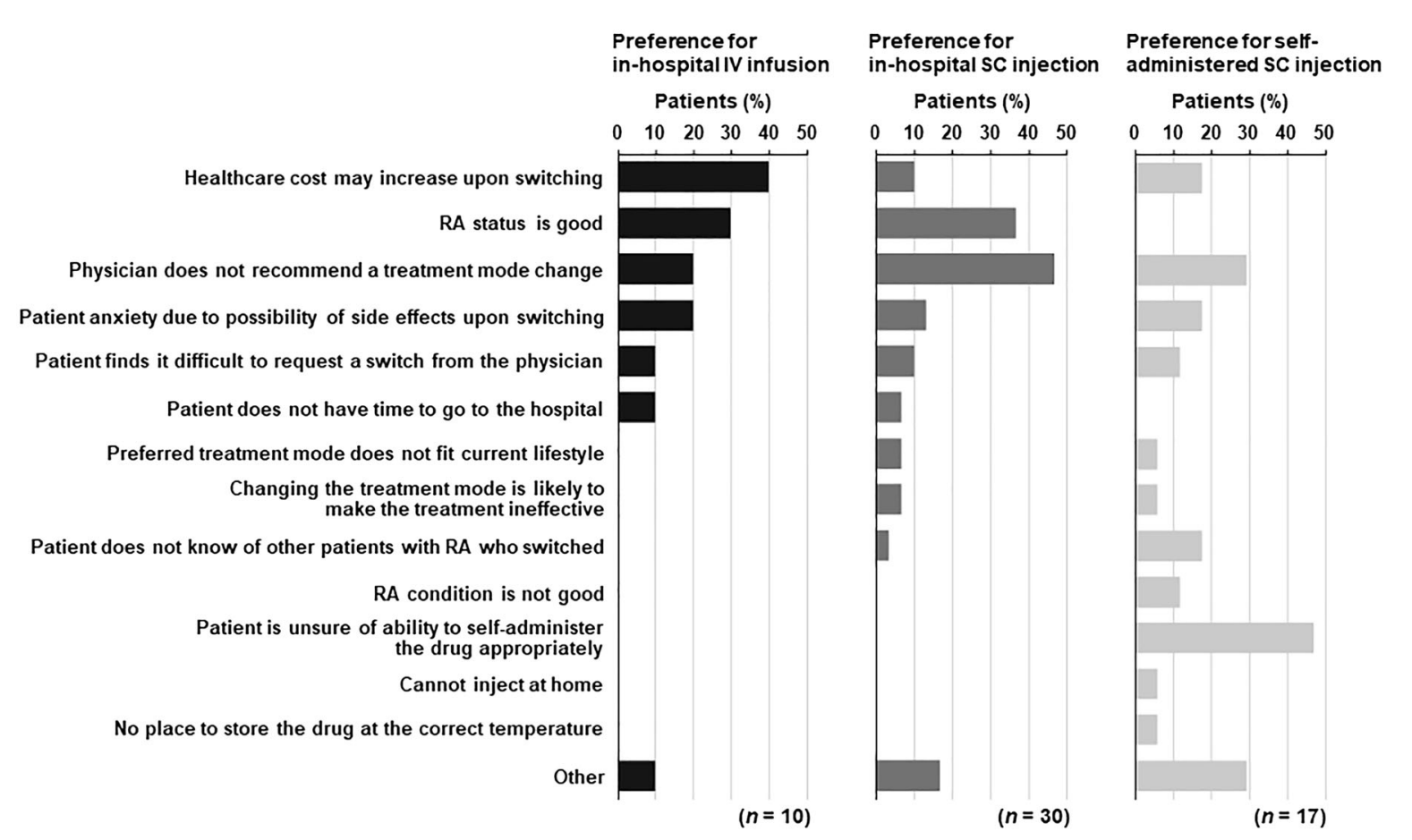

Fig. 5 Reasons why patients did not receive their preferred treatment mode by treatment mode preference. Patients could select multiple answers

Reasons for changing treatment mode of bDMARDs in the future (\%)

Change of RA symptoms (improved or worsened)

Switching recommended by a medical professional (e.g., physician or nurse)

\section{New drug released \\ Patient age increased}

Income increased/decreased

Patient academic or work environment changed (e.g., receiving further education, job transfer, retirement)

Patient living conditions changed (e.g., marriage, childcare, nursing care)

Effect of "word of mouth" (e.g., recommendation by other patients who had good experiences of other treatment modes)

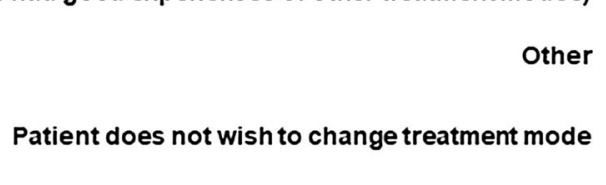

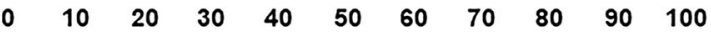

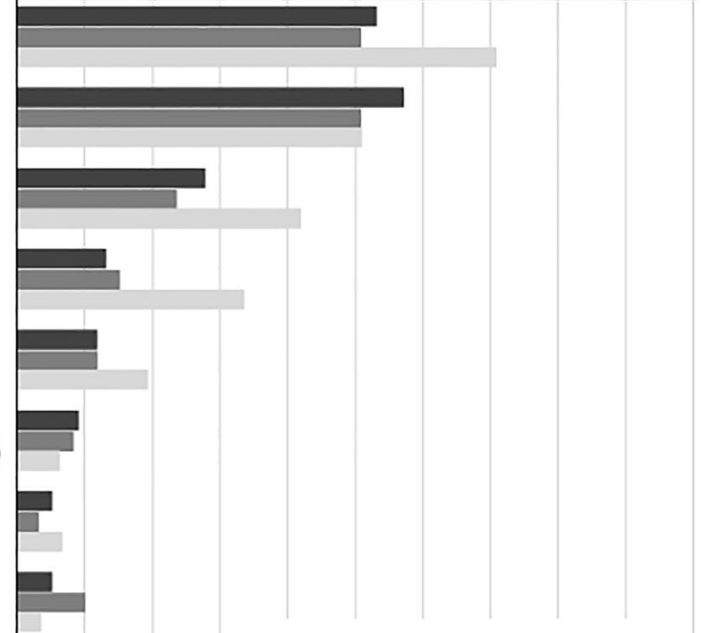

1

In-hospital IV infusion $(n=75)$

In-hospital SC injection ( $n=59$ )

Self-administered SC injection $(n=266)$

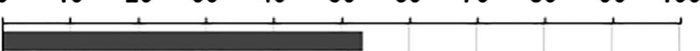

Fig. 6 Reasons for changing treatment mode of bDMARD in the future. Patients could select multiple answers 
$98.1 \%(261 / 266)$ for self-administered SC injection.

\section{DISCUSSION}

In this web-based survey, we found that a higher current frequency of hospital visits and anxiety or other hurdles related to self-administered SC injection were significant patient background factors for a preference for in-hospital IV infusion and in-hospital SC injection, and younger age for a preference for in-hospital SC injection, over self-administered SC injection. Conversely, a flexible administration setting was a significant patient-related factor for a preference for self-administered SC injection. Many patients reported that they were already receiving their preferred treatment mode. However, more than $90 \%$ of patients responded that they would like to change their treatment mode of bDMARD in the future if recommended to do so by a medical professional, or due to aging or a change in RA symptoms. These findings suggest that changes in patient background which affect the preferred treatment mode should be considered in decision-making for RA therapy with bDMARDs.

In this survey, the percentage of patients by current bDMARD treatment mode was $18.8 \%$ for in-hospital IV infusion, $14.8 \%$ for in-hospital SC injection, and $66.5 \%$ for self-administered SC injection. Compared with the USA, the proportion of patients using IV infusion was higher in this survey, but similar to that in the EU [9].

Among patient background factors, a higher current frequency of hospital visits and anxiety or other hurdles related to self-administered SC injection contributed to patients' preferences for in-hospital IV infusion and in-hospital SC injection. Patients who do not experience any challenges in attending hospital appointments and/or have anxiety or other hurdles related to self-administered SC injection tend to prefer hospital-based administration of bDMARDs. Among patients currently receiving in-hospital IV infusion, $68.0 \%$ expressed anxiety or other hurdles related to self-administered SC injection, as did $72.9 \%$ of those currently receiving in-hospital SC injection (data not shown). These findings emphasize the importance of communication between patients and physicians about anxiety and other hurdles related to self-injection.

With regard to self-administered SC injection, the major patient background factor that affected patient preference for this mode was its flexible administration setting. A second factor associated with a greater preference for self-administered SC injection over in-hospital SC injection was younger age $(<40$ years compared with $\geq 60$ years). A 2008 study of patient preferences among three groups of TNFi-naïve patients receiving three TNFis found that, as in our present study, older patients were more likely to prefer in-hospital dosing, whereas nonelderly adults were more likely to prefer selfadministration [11]. Our present findings also suggest that young adult patients and patients with time limitations due to employment, academic practice, or parenting/caregiving commitments would prefer self-administered SC injection, due to its minimization of hospital visit frequency and freedom to choose the time and place of administration.

Many patients did not report a discrepancy between their current and preferred treatment mode. Reasons included general satisfaction with the current treatment mode and the opinion that the current treatment mode fit their current lifestyle. The proportion of patients reporting that their current treatment mode fit their current lifestyle was higher in patients receiving self-administered SC injection. Moreover, patients currently receiving bDMARDs via in-hospital IV infusion reported anxiety over whether the drug's effect would be lost if the treatment mode were changed. In other words, patients receiving in-hospital IV infusion of a bDMARD tended to focus on the effectiveness of the medication, whereas those receiving self-administered SC injection were influenced by the relationship between their treatment mode and lifestyle.

In contrast, $32.0 \%$ of patients currently receiving in-hospital IV infusion, $28.8 \%$ receiving in-hospital SC injection, and $6.0 \%$ receiving self-administered SC injection reported a discrepancy between their current and preferred 
treatment mode. The primary reasons patients were unable to receive their preferred treatment mode were as follows: patients who preferred in-hospital IV infusion were concerned that the change would result in higher healthcare costs; patients who preferred in-hospital SC injection were concerned that their physician would not recommend a change in treatment mode; and those who preferred self-administered SC injection were anxious about being unable to administer the treatment appropriately, and were concerned that their physician would not recommend the treatment mode change. We suggest that better communication between physicians and patients on treatment mode selection might likely alleviate such concerns and increase the proportion of patients receiving bDMARDs via their preferred route of administration.

We also investigated the possibility of future bDMARD treatment mode changes. While many patients reported no discrepancy between their current and preferred mode, $>90 \%$ also reported that they might want to change their mode in the future following a recommendation to do so by a medical professional, or due to aging or a change in RA symptoms. More than one half of the respondents wanted to change their treatment mode if their RA symptoms changed. This rate was higher among those using self-administered SC injection than the other two modes. Accordingly, these patients may be willing to receive treatment at a hospital if their symptoms worsen. Regardless of the current treatment mode, more than one half of respondents in this study were willing to change their treatment mode if recommended to do so by a medical professional. This result is thought to reflect the very high dependency of most RA patients on their medical professional when deciding on treatment modes [16]. In addition, a higher percentage of patients who used self-administered SC injection than those who used other modes indicated that they would like to change their method of administration "when patient age increased." This finding supports a previous finding that elderly people preferred their treatment to be administered by healthcare providers [11], and suggests that patients feel anxious about continuing self-administered SC injection as they age. It is therefore necessary to confirm whether patients who are self-administering their medication are willing to change this treatment mode as they age. Ensuring that changes in patient preference are not overlooked requires the implementation of SDM in daily practice as a suitable means for both physicians and patients to reach consensus and improve treatment satisfaction [17].

This survey was carried out between October and November of 2020. The spread of COVID19 infection during that period may have affected the selection of and preference for treatment mode among patients with RA. When surveyed on this topic, $97 \%$ of patients responded that their treatment mode had not changed, and $85.8 \%$ did not wish to change their treatment mode at the time of the survey or in the future. This result suggests that this survey was hardly affected by COVID-19.

\section{Limitations}

This web-based survey has several limitations. First, the survey was limited to respondents who had internet access, raising concerns about bias in age groups given that elderly patients have lower internet usage than non-elderly patients [18]. However, mean patient age in this survey was similar to those reported in large observational studies in Japan [19-21]. In addition, mean disease duration was also similar to those reported in the above studies [19-21]. Second, we were unable to assess disease activity by physical examination or laboratory investigation, and therefore did not assess the Disease Activity Score 28 (DAS28). In addition, we did not include Routine Assessment of Patient Index Data 3 (RAPID3) items. Instead, we used the J-HAQ instrument, whose use in measuring functional status in RA patients is validated [15]. Third, approximately $25 \%$ of patients with spondyloarthritis were reported to have extended their dosing intervals or to have discontinued bDMARD therapy during the COVID-19 pandemic [22]; however, we did not evaluate dosing intervals in this study. 


\section{CONCLUSIONS}

Selection of treatment mode in patients receiving bDMARDs for RA is affected by the frequency of current hospital visits, as well as age, flexible administration setting, and anxiety or other hurdles regarding self-injection. Of note, while many patients reported already receiving a favorable treatment mode, $>90 \%$ wanted to change to a different mode in the future if recommended to do so by health professionals, or if required by aging or a change in RA symptoms. During long-term RA treatment with bDMARDs, patient preferences for treatment mode following a change in their background should always be confirmed through physician-patient communication. SDM is effective for determining the patients' preferred treatment mode of bDMARD, and is expected to become standard practice.

\section{ACKNOWLEDGEMENTS}

Funding. Sponsorship for this study and article processing charges were jointly provided by Mitsubishi Tanabe Pharma Corporation (Osaka, Japan) and Janssen Pharmaceutical K.K. (Tokyo, Japan).

Authorship. All named authors meet the International Committee of Medical Journal Editors (ICMJE) criteria for authorship for this article, take responsibility for the integrity of the work as a whole, and have given their approval for this version to be published.

Authors' Contributions. Mitsumasa Kishimoto and Fumiko Yamairi made substantial contributions to the study conception, study design, study protocol, data interpretation, and writing or critical review of the manuscript for important intellectual content. Noriko Sato, Jun Kobayashi, and Saori Yamauchi made substantial contributions to the study conception, study design, data interpretation, and critical review of the manuscript for important intellectual content. Tomohisa Iwasaki made substantial contributions to the study design, study protocol, analysis, or data interpretation, and critical review of the manuscript for important intellectual content. All authors had full access to the study data and have read and approved the final manuscript.

Medical Writing and Other Assistance. The authors thank all respondents for completing the questionnaire, and QLife Inc., who assisted with the administration of the questionnaire, data aggregation, and statistical analysis. The authors would like to thank Yutaka Ishii and Seiji Yokoyama (Immunology, Infectious Diseases \& Vaccine Department, Medical Affairs Division, Janssen Pharmaceutical K.K.) for their contribution to the data interpretation and discussion. Medical writing assistance in the preparation of this article was provided by Dr Matthew Glasgow of Edanz Pharma. Final editing of the submitted manuscript was provided by Guy Harris of DMC Corp. Support for this assistance was funded by Mitsubishi Tanabe Pharma Corporation (Osaka, Japan) and Janssen Pharmaceutical K.K. (Tokyo, Japan).

Disclosures. Mitsumasa Kishimoto has received advisory board fee and lecture fees from AbbVie, Amgen, Astellas Pharma, BristolMyers Squibb, Celgene, Eli Lilly Japan, Gilead Sciences, Janssen Pharmaceuticals, Kyowa Kirin, Mitsubishi Tanabe Pharma Corporation, Novartis Pharma, Ono Pharmaceutical, Pfizer Japan, and UCB Japan; and lecture fees from Asahi Kasei Medical, AYUMI Pharmaceutical, Boehringer Ingelheim, Celltrion Healthcare Co., Ltd., Chugai Pharmaceutical, Daiichi Sankyo, Eisai, and Teijin Pharma. Fumiko Yamairi, Noriko Sato, Jun Kobayashi, Saori Yamauchi, and Tomohisa Iwasaki are employees of Mitsubishi Tanabe Pharma Corporation.

Compliance with Ethical Guidelines. The study was conducted in compliance with the Declaration of Helsinki of the World Medical Association (revised October 2013) and the Ethical Guidelines for Medical and Health Research Involving Human Subjects (partially revised on 28 February 2017). Approval of this study was obtained from the Clinical Research 
Review Board of Takahashi Clinic on 20 October 2020. This study was registered in the UMIN clinical trial registry (registration number: R000048089).

Data Availability. The data underlying this article are available from Mitsubishi Tanabe Pharma Corporation (rpp_mtpc@cc.mt-pharma.co.jp) or the corresponding author upon reasonable request.

Open Access. This article is licensed under a Creative Commons Attribution-NonCommercial 4.0 International License, which permits any non-commercial use, sharing, adaptation, distribution and reproduction in any medium or format, as long as you give appropriate credit to the original author(s) and the source, provide a link to the Creative Commons licence, and indicate if changes were made. The images or other third party material in this article are included in the article's Creative Commons licence, unless indicated otherwise in a credit line to the material. If material is not included in the article's Creative Commons licence and your intended use is not permitted by statutory regulation or exceeds the permitted use, you will need to obtain permission directly from the copyright holder. To view a copy of this licence, visit http:// creativecommons.org/licenses/by-nc/4.0/.

\section{REFERENCES}

1. Aletaha D, Smolen JS. Diagnosis and management of rheumatoid arthritis: a review. JAMA. 2018;320: 1360-72.

2. Smolen JS, Landewé RBM, Bijlsma JWJ, et al. EULAR recommendations for the management of rheumatoid arthritis with synthetic and biological disease-modifying antirheumatic drugs: 2019 update. Ann Rheum Dis. 2020;79:685-99.

3. Japan College of Rheumatology. Guidance of denosumab use for rheumatoid arthritis. 2nd Edition 2020 (in Japanese). 2018. https://www. ryumachi-jp.com/publish/guide/guideline_ denosumab/. Accessed 31 Mar 2021.
4. Singh JA, Saag KG, Bridges SL Jr, et al. 2015 American College of Rheumatology guideline for the treatment of rheumatoid arthritis. Arthritis Care Res (Hoboken). 2016;68:1-25.

5. Yamanaka H, Tanaka E, Nakajima A, et al. A large observational cohort study of rheumatoid arthritis, IORRA: providing context for today's treatment options. Mod Rheumatol. 2020;30:1-6.

6. Tada K, Yamaji K, Tamura N. New therapy in rheumatoid arthritis-biological DMARDs and JAK inhibitors. Juntendo Med J. 2020;66:34-7.

7. Alten R, Krüger $\mathrm{K}$, Rellecke $\mathrm{J}$, et al. Examining patient preferences in the treatment of rheumatoid arthritis using a discrete-choice approach. Patient Prefer Adher. 2016;10:2217-28.

8. Emadi SA, Hammoudeh M, Mounir M, Mueller RB, Wells AF, Sarakbi HA. An assessment of the current treatment landscape for rheumatology patients in Qatar: recognising unmet needs and moving towards solutions. J Int Med Res. 2017;45:733-43.

9. Taylor PC, Betteridge N, Brown TM, et al. Treatment mode preferences in rheumatoid arthritis: moving toward shared decision-making. Patient Prefer Adher. 2020;14:119-31.

10. Edel Y, Sagy I, Pokroy-Shapira E, et al. A cross-sectional survey on the preference of patients with rheumatoid arthritis for route of administration of disease-modifying anti-rheumatic drugs: oral target-specific versus parenteral biologic. Isr Med Assoc J. 2020;22:154-9.

11. Chilton F, Collett RA. Treatment choices, preferences and decision-making by patients with rheumatoid arthritis. Musculoskeletal Care. 2008;6: $1-14$.

12. Nolla JM, Rodríguez M, Martin-Mola E, et al. Patients' and rheumatologists' preferences for the attributes of biological agents used in the treatment of rheumatic diseases in Spain. Patient Prefer Adher. 2016;10:1101-13.

13. Reilly MC, Zbrozek AS, Dukes EM. The validity and reproducibility of a work productivity and activity impairment instrument. Pharmacoeconomics. 1993;4:353-65.

14. Reilly Associates. Work Productivity and Activity Impairment Questionnaire: General Health V2.0 (WPAI:GH). (in Japanese). http://www. reillyassociates.net/wpai-gh_v2.0-japanese japan_-debriefed.doc. Accessed 31 Mar 2021.

15. Matsuda Y, Singh G, Yamanaka H, et al. Validation of a Japanese version of the Stanford Health Assessment Questionnaire in 3,763 patients with 
rheumatoid arthritis. Arthritis Rheum. 2003;49: 784-8.

16. de Toro J, González CM, Cea-Calvo L, et al. Patients' perceptions on shared decision making during prescription of subcutaneous biological drug treatments for inflammatory arthritis: The RHEU-LIFE survey. Musculoskeletal Care. 2020;18:568-74.

17. Mahlich J, Schaede U, Sruamsiri R. Shared decisionmaking and patient satisfaction in Japanese rheumatoid arthritis patients: a new "preference fit" framework for treatment assessment. Rheumatol Ther. 2019;6:269-83.

18. Ministry of Internal Affairs and Communications. Internet use in Japan. (in Japanese). https://www. soumu.go.jp/johotsusintokei/whitepaper/ja/r02/ html/nd252120.html. Accessed 31 Mar 2021.

19. Mori H, Sawada T, Nishiyama S, et al. Influence of seasonal changes on disease activity and distribution of affected joints in rheumatoid arthritis. BMC Musculoskelet Disord. 2019;20:30.

20. Nakayama M, Furuya T, Inoue E, et al. Factors associated with osteoporosis medication use in Japanese patients with rheumatoid arthritis: results from the Institute of Rheumatology Rheumatoid Arthritis cohort study. Osteoporos Sarcopenia. 2020;6:82-7.

21. Nakajima A, Sakai R, Inoue E, Harigai M. Prevalence of patients with rheumatoid arthritis and agestratified trends in clinical characteristics and treatment, based on the National Database of Health Insurance Claims and Specific Health Checkups of Japan. Int J Rheum Dis. 2020;23: 1676-84.

22. Rosenbaum JT, Hamilton H, Choi D, Weisman MH, Reveille JD, Winthrop KL. Biologics, spondylitis and COVID-19. Ann Rheum Dis. 2020;79:1663-5. 